\title{
Impact and adaptation to flooding: A focus on water supply, sanitation, and health in rural communities on the Barotse floodplain in Zambia
}

Inonge D. MILUPI ( $\square$ inongemilupi69@gmail.com )

The University of Zambia

Corinne Schuster Wallace

University of Saskatchewan

Craig Janes

University of Waterloo

\section{Research Article}

Keywords: Adaptation, flood, health, impact, water supply, sanitation

Posted Date: February 14th, 2022

DOI: https://doi.org/10.21203/rs.3.rs-1283256/v1

License: (c) (1) This work is licensed under a Creative Commons Attribution 4.0 International License.

Read Full License 


\section{Abstract}

Globally it is recognised that climate change impact is manifested through severe weather events that cause, for example, flooding. Floods have large social consequences for communities and individuals. This paper investigates the impact of flooding on water supply and sanitation conditions together with flood-induced health problems on the Barotse floodplain in Zambia. The study also explored rural response measures and adaptation strategies. This study relied on intensive field investigation in May 2021 where 99 households from different villages in the floodplain were randomly sampled to participate in a questionnaire survey. Key informants, including government officials from the Ministries of Health, Agriculture, and Local Government and Housing, were also interviewed. The findings showed that water supply and sanitation conditions are severely interrupted during flood periods, and this leads to various waterborne diseases. The findings further revealed that all pit latrines in the study area become submerged and therefore unsafe to use. Adaptation measures include boiling water before use and water disinfection using chlorine. Other, adaptive measures noted in the study area include open water defecation due to inundation of toilets, which further contaminates drinking water supplies.

Based on the findings, the researchers propose that the government and other stakeholders should prioritise flood-proof water and sanitation facilities in the study area in order to improve the health of the rural community during floods.

\section{Background}

Several scholars such as [1] have noted that climate change impacts such as floods threaten water, sanitation, and hygiene (WASH) facilities and services. Much of the historical and contemporary view of flooding is that it is a hazard which threatens property and life, as well as development and social activity [2]. Floods challenge the normal functions of life, affecting homesteads, agricultural land, daily activities, water supply, sanitation conditions, and infrastructure as well as adversely impacting WaSH access and human health $[3,4]$. During a flood, water sources become contaminated, enhancing the spread of waterborne diseases, and adversely impacting human health [5]. Other immediate impacts of flooding include loss of human life, damage to property, destruction of crops, and loss of livestock [6]. Because flood impacts are increasing in many parts of the world, understanding the primary drivers of changes in risk are essential for effective adaptation [7]. Floods affect both individuals and communities, and have social, economic, and environmental consequences [8]. The consequences of floods, both negative and positive, vary greatly depending on the location and extent of flooding, as well as the vulnerability $[9,10]$. In addition, $[9,10]$ further identified the value of the natural and constructed environments they affect to be a consequence of floods. An individual or a society with a low perception of risk is likely to adjust poorly to the threat while people with a high sensitivity to risk are likely to behave in a positive way to adapt in the face of nature's threats [6].

Flood is a common feature in the Barotse floodplain of Zambia. The natural environment is characterised by annual floods that occur between December and July, with floods peaking in April and receding by 
July [11]. In recent years, variability in the timing and intensity of floods has challenged the traditional adaptive strategies employed by communities on the floodplain [12]. The timing of the floods according to [12] has equally changed with both delaying and early onset happening more frequently leading to an increase in struggles in flood forecast and preparation using TEK consequently creating greater damages to crops, livestock, and houses. The impact of climate change on the timing and intensity of floods in the Barotse floodplain was also observed by [13] who noted the changes in catchment response as a result of climate change and variability in the study area. Loss of crops due to flooding is now a common annual occurrence that results in food insecurity [14]. As such, the annual flooding regime in the Barotse floodplain has an important influence on the livelihoods and economies of households that practice agriculture on the plains, particularly as it forces seasonal migration of people and livestock to higher ground during flooding. For those who remain, safe water supply and sanitation are severely affected by flooding in the floodplain [15]. The vulnerability of the rural poor to floods therefore increases due to lack of effective initiatives to manage water supply, sanitation, and health hazards during the flood period. To understand the challenges faced and local solutions implemented to protect health during flood events in the Barotse floodplain this study a) investigates the extent of impact of flood on water supply, sanitation, and health of the rural poor; and (b) proposes effective adaptation measures and strategies.

\section{Study Area}

The Barotse floodplain is very flat and is inundated by the Zambezi River for three to five months per year, from December to July [11]. The Barotse floodplain is also known as the Bulozi Plain, Lyondo, or Zambezi floodplain [16] The Barotse floodplain is one of Africa's greatest wetlands and the second largest wetland in Zambia after Lake Bangweulu, extending $230 \mathrm{~km}$ from north to south and reaching widths of up to $50 \mathrm{~km}$ [11]. It is in Zambia's Western Province, $600 \mathrm{~km}$ west of Zambia's capital city Lusaka (Figure 1).

The Barotse floodplain is an area with high ecological and agricultural potential although it is characterised by widespread poverty among its inhabitants [17]. Barotse floodplain has a population of 33000 [12]. Although many ethnic groups are found in Western Province, the area is mainly the homeland of the Lozi or Barotse people, who were previously known as Luyi [18]. This group of people derive various livelihoods from the floodplain, including cattle husbandry, fishing and farming. The traditional authority of the area is the "Barotse Royal Establishment" (BRE). This institution is led by a paramount authority, the Litunga (Owner of the Land) who is assisted by traditional ministers locally known as Indunas. The Barotse is famous for its cultural heritage, especially the Kuomboka ceremony (a Silozi word which means coming out of water), when the Litunga leaves his dry season capital, Lealui, in the plain, to move to his palace of Limulunga on the upper land. The Kuomboka ceremony is an annual relocation of people, their cattle, and the Litunga. It is a highly celebrated traditional ceremony that draws large numbers of visitors and tourists $[19,16]$.

\section{Methods}




\section{Study design, data collection and analysis}

This study was based on secondary and primary data collected in May 2021. Secondary data were derived from published materials and policy documents, whereas primary data were collected through two methods: household surveys, and key-informant (KI) interviews. The KI interviews were conducted with local government officials (KI_G) and traditional leaders (village headsmen) (KI_T). Ethical clearance for this work was received from the University of Waterloo (\# 43389) and the University of Zambia (HSSREC 2021- May- 007). Secondary data included government documents such as the [20, 21, 22]. A document analysis provided a better understanding of the local impacts of flood on water supply and sanitation conditions as well as flood induced health problems. These documents provided background information for the research and facilitated research design. Quantitative data from the household surveys were analysed using the Statistical Package for Social Sciences (SPSS V23) to generate frequencies of responses.

\section{Household Survey}

Household surveys generated quantitative and qualitative data through structured researcheradministered questionnaires, which comprised both closed and open-ended questions. The survey explored flood impacts on water supplies and sanitation, as well as health and adaptation strategies. Ninety-nine households across 10 communities participated in the study. The sampling unit for the study area was the household, with the target respondent being the household head or the female counterpart over the age of 18 . Households were randomly selected. The sample size for the study was determined using the sample size calculator (https: //surveysystem.com/sscalc.htm). The confidence interval for Barotse floodplain sample size at a confidence level of $95 \%$ was 9.8 . This means that the sample size of 99 captured the mean of the population in the study area. To ensure that the questionnaire was suited to the context, a pre-test was conducted in Lealui village. Because there were not changes to the instrument following the pretest, the data from the pre-test are included in the analysis. Both men and women were interviewed during the survey. The interviews were conducted by the lead researcher (Milupi), assisted by seven research assistants. The research assistants, conversant in the local language (Silozi), were trained before conducting interviews. They collected the responses in written form. Interviews were conducted in Silozi, translated into English, and digitised into Excel before the quantitative data were imported into SPSS.

The households were interviewed regarding the following aspects of impact and adaptation to flood in Barotse floodplain:

- Assessment of health, water and sanitation facilities, and prevalence of water borne diseases during flood

- Type of sanitation facility used during floods

- Quality of drinking water during the floods 
- The perceived prevalence of water borne diseases

- Reporting of the main illnesses experienced during the floods

- Access to safe drinking water

- Coping strategies and government support

\section{Key-Informant Interviews}

Key informants (KIs) included government officials (KI_G) from the Ministries of Health, Agriculture, and Local Government and Housing from Mongu as well as village headmen (KI_T). Government officials were interviewed in English, while village headmen were interviewed in Silozi. The responses of the village headmen were transcribed in Silozi and then later translated into English. The traditional leaders were asked questions about their role in problems associated with water supply, sanitation, and health caused by the flood in the floodplain and government officials were asked about the performance of water, sanitation, and hygiene (WASH) facilities in Barotse floodplain.

\section{Results}

In total, 99 household heads and 10 key informants were interviewed. Of the household respondents interviewed, 50 identified as men while 49 identified as women. Two thirds of household respondents reported secondary education (66 respondents) while one third had no or primary education (33 respondents). Almost two thirds of respondents (63 respondents) were born in the community. Thirtyeight respondents identified as younger than 35 , with an additional 44 participants between the age of 35 and 49, and 17 respondents 50 or older (Table 1 ). Ninety respondents reported a family size between four and twelve people, and almost two-thirds (61) reported family sizes of six to nine people. Seventy-five respondents reported between one and four under five-year-olds in the household.

Table 1

Demographic characteristics of respondents 
$N=99$

\begin{tabular}{ll}
\hline \multicolumn{1}{c}{ Sex } & \\
\hline Female & $49(49 \%)$ \\
\hline Male & $50(51 \%)$ \\
\hline Age & \\
\hline $18-19$ & $2(2 \%)$ \\
\hline $20-24$ & $16(16 \%)$ \\
\hline $25-29$ & $12(12 \%)$ \\
\hline $30-34$ & $8(8 \%)$ \\
\hline $35-39$ & $22(22 \%)$ \\
\hline $40-44$ & $13(13 \%)$ \\
\hline $45-49$ & $9(9 \%)$ \\
\hline 50 years and above & $17(17 \%)$ \\
\hline \multicolumn{1}{c}{ Education } & $3(3 \%)$ \\
\hline Junior Primary (Grade 1-4) & $34(34 \%)$ \\
\hline Junior Secondary (Grade 8-9) & $3(3 \%)$ \\
\hline None & $28(28 \%)$ \\
\hline Senior Primary (Grade 5- 7$)$ & $31(31 \%)$ \\
\hline Senior Secondary (Grade 10-12) &
\end{tabular}

\section{Access to drinking water during the floods}

Over three quarters of respondents (79\%) rated their water supply as bad or very bad. Most survey respondents ( $81 \%$; $52 \%$ women and $48 \%$ men) indicated that surface water from rivers and streams was their main source of drinking water during the dry season. Seventeen respondents reported using the floodwaters and two used a pump. This compares to 91 respondents using surface water in the dry season, six using a dug well, and one using a pump. In addition to drinking, this water is used for cooking (71 respondents), washing (83 respondents), and bathing (57 respondents). Twenty respondents used the water for gardening, animals, or watering.

Challenges associated with access to drinking water during the flood were predominantly associated with difficulty traveling (23 respondents) or the need for a boat, whether they did not have one and needed one, 
or had one that could be used (36 respondents). Nine respondents indicated no access at all during floods, and four identified crocodiles as a challenge for accessing water during the flood. This range of access behaviours was confirmed by the village headmen. While some individuals who owned a canoe stated that they used it to collect water outside the flood, i.e., many reported using it to go to the middle of the river to collect water from the original river channel. One KI noted that open wells usually become nonusable during the flood months because they are mostly covered by the flood waters:

"We drink from the flood waters during flood because our water sources are usually covered by the floods." (KI_T1)

With regard to the main source of water in Barotse floodplain, the study showed that surface water was their main source of drinking water in both the rain and dry season. (Table 2).

Table 2

Showing cross tabulation of main source of water during flood and dry season

Main Water Source of Drinking water in the rain season

Main Water Source of Drinking water in the dry season

\begin{tabular}{|c|c|c|c|}
\hline Other & $\begin{array}{l}\text { Surface water } \\
\text { (river, stream) }\end{array}$ & $\begin{array}{l}\text { Unprotected dug } \\
\text { well(open) }\end{array}$ & Total \\
\hline
\end{tabular}

\begin{tabular}{lllll}
\hline Hand pump & 1 & 1 & 0 & 2 \\
\hline Other & 1 & 12 & 4 & 17 \\
\hline Surface water (river, stream) & 0 & 77 & 3 & 80 \\
\hline Total & 2 & 90 & 7 & 99
\end{tabular}

Impact of flood on water sources

Responses regarding the impact of flooding on water sources indicated that most respondents (63\%) reported that flood contaminates water sources (63\%), and this causes diseases (5\%) in the study area. Other impact of water sources shown in the study area included flood covering water sources $(18 \%)$, increase in depth (1\%) and fear of crocodiles (5\%). Some respondents (6\%) however said floods had no impact on their water sources in Barotse floodplain. The impact of flood on water sources was further confirmed by one respondent who said the following words: -

"Our sources of drinking water become dirtier because there is too much dirty in floods as it takes with the particles found on land e.g dead snakes, animals and it also washes away toilets"

\section{Impact of flood on water quality}

Page $7 / 21$ 
Figure 2 indicates that most respondents believed the quality of water during flood is poor (42\%) and dirty (36\%). Of the remaining respondents, $12 \%$ said that the water is contaminated during flood while $6 \%$ said that water is degraded during the flood. Two percent of respondents said that flood has no impact on water quality and $1 \%$ did not answer.

Most respondents (85\%) report that they have not undertaken any measures to protect the main sources of water during flood in the study area:

"We have done nothing because it is not possible to stop floods from mixing with our main source of drinking water." Survey Respondent

The study further shows that only $2 \%$ of respondents treat their water with chlorine and another $2 \%$ boil their water before use. The remaining ( $5 \%$ ) believe that their body has immunity to protect them when they take dirty or contaminated water. Three percent of respondents however do protect their wells during flood (table 3).

Table 3

showing responses on adaptation measures taken to protect main water sources

\begin{tabular}{|lll|}
\hline Adaptation measure & Frequency & Percent \\
\hline Nothing & 85 & 85 \\
\hline Add Chlorine & 2 & 2 \\
\hline Boiling & 2 & 2 \\
\hline Natural immunity & & 5 \\
\hline Protect wells & 3 & 3 \\
\hline No response & 1 & 1 \\
\hline Total & 99 & 100 \\
\hline
\end{tabular}

Regarding safe drinking water supply during floods, most respondents (41\%) were of the view that the government should be providing them with chlorine during floods to purify their water while $31 \%$ proposed the drilling of boreholes by the government in the study area. Of the remaining respondents, $18 \%$ proposed provision of water pumps and $4 \%$ suggested boiling of water. $2 \%$ of respondents did not suggest anything. The remaining 3\% argued for sensitization programmes on health issues (Table 4). To address the impact of flooding on drinking water quality and availability in Barotse floodplain, Kls stated that the government should provide potable water and mobile water dispensing units. There should also 
be deliberate distribution of chlorine to the floodplain members and construction of boreholes on the isolated raised grounds found in the floodplain.

Table 4

showing responses on what government should do to provide safe drinking Water

\begin{tabular}{|lll|}
\hline Role of Government & Frequency & Percent \\
\hline Chlorine provision & 41 & 41 \\
\hline Drilling of Boreholes & 31 & 31 \\
\hline Water pump provision & 18 & 18 \\
\hline Boiling the water & 4 & 4 \\
\hline Sensitisation activities & 3 & 3 \\
\hline No suggestion & 2 & 2 \\
\hline Total & 99 & 100 \\
\hline
\end{tabular}

\section{Access to sanitation}

When asked to rate access to improved sanitation, $60 \%$ rated facilities as bad or very bad. During nonflood periods, $81.8 \%$ of respondents indicated that they practiced open defecation, with only $10 \%$ using a household facility. This was further corroborated by participants reporting that sanitation facilities are not close to their households (59.6\%). While $15.1 \%$ of respondents did not provide a distance, $36.4 \%$ of respondents who indicated that sanitation facilities were far away also indicated that they were at least $200 \mathrm{~m}$ away from the household. However, village headsmen disagreed, saying that pit latrines were commonly used during the dry season, rather than open defecation. $35.4 \%$ of respondents said that they altered their sanitation practices during flood events. This was predominantly from open defecation to water-based defecation (26.3\% respondents). Of those who changed practices, there is no significant difference between men and women regarding use of sanitation facilities (Table 4). However, when asked about the impact of floods on sanitation, $61.6 \%$ of respondents indicated that the floods compromise sanitation in some way, such as making it difficult. Despite this, $60.6 \%$ of respondents indicated that they did nothing to adapt sanitation practices during floods, $16.2 \%$ of indicated that they switch to water defecation, and $12.1 \%$ of indicated that they move (Table 5). Both groups of Kls noted that pit latrines are usually submerged during the floods and that a lack of permanent sanitation facilities led to open defecation. Overwhelmingly, respondents reported that the government did nothing to help them with improved sanitation during the floods ( $94.9 \%$ respondents), with $4.0 \%$ of respondents indicating that the government had built new latrines. On the type of sanitation common during floods and dry season (table 6) indicated that open defecation was common in both seasons. 
Table 5

Type of sanitation facility used and perceived prevalence of health concerns

$n(\%)$ of Total Female $n(\%)$

\begin{tabular}{|c|c|c|}
\hline \multicolumn{3}{|l|}{ Sanitation Type } \\
\hline Community latrines & $6(6.1)$ & $2(33.3)$ \\
\hline Household facility & $10(10.1)$ & $4(40)$ \\
\hline Improved & $1(1)$ & $1(100)$ \\
\hline Open defecation & $81(81.8)$ & 42(51.9) \\
\hline Other (specify) & $1(1)$ & $1(100)$ \\
\hline \multicolumn{3}{|c|}{ Perceived prevalence of water borne diseases } \\
\hline Very Low & $16(16.2)$ & $6(37.5)$ \\
\hline Low & $8(8.1)$ & $3(37.5)$ \\
\hline Moderate & $7(7.1)$ & $4(57.1)$ \\
\hline High & $10(10.1)$ & $5(50)$ \\
\hline Very High & $58(58.6)$ & $32(55.2)$ \\
\hline \multicolumn{3}{|c|}{ Common health problems } \\
\hline Malaria & $58(58.6)$ & $27(46.6)$ \\
\hline Diarrhoea & $33(33.3)$ & 19(57.6) \\
\hline Dysentery & $7(7.1)$ & $4(57.1)$ \\
\hline Others & $1(1)$ & $0(0)$ \\
\hline
\end{tabular}

Table 6

Showing the type of sanitation during flood and dry season 


\begin{tabular}{|lll|}
\hline Type of sanitation & Dry (\%) & Flood (\%) \\
\hline Open defecation & 82 & 3 \\
\hline Water defecation & 0 & 28 \\
\hline House & 10 & \\
\hline community & 4 & \\
\hline Pit latrines & 1 & \\
\hline Burry faeces & 1 & \\
\hline Dry toilets & 0 & 4 \\
\hline No change & & 1 \\
\hline Did not answer & & 49 \\
\hline Missing & 1 & 15 \\
\hline
\end{tabular}

When asked about what they think should be done in the Barotse floodplain to address the impact of flood on sanitation, most survey respondents (79\%) wanted the government to build flood resistant toilets for them on high land which does not get flooded easily. Some respondents (3\%) proposed the building of floating toilets by the government while others (4\%) said building concrete pit latrines on mazulu (islands) (4\%) would be the best. Of the remaining (13\%) of the respondents, $(7 \%)$ said nothing can be done as all the land gets flooded and $5 \%$ of respondents did not suggest anything. The remaining (1\%) of respondents suggested carrying out community sensitisation programmes in the study areas on the importance of good hygiene.

In terms of sanitation, $\mathrm{KI} 1$ suggested construction of raised concrete and portable (mobile) toilets in the floodplain. Ultimately, government policies clearly indicate a commitment to water and sanitation for all, while delivering on this commitment in the floodplain is problematic.

\section{Self-reported health impacts of floods}

Reports of poor access to potable water and adequate sanitation facilities were reflected in the poor selfreported health status of children, women, men, and communities. When asked to rate the health of children under the age of five during flood periods, almost half of respondents (47.5\%) indicated that it was very bad, while an additional $40.0 \%$ rated it as bad. Children's and community health were rated lower than women's health by household respondents, but the traditional leaders said that the children were most affected, followed by women. During the flood period, most respondents (58\%) rated the health of the community as very bad, with an additional $28.3 \%$ rating it as bad (Figure 3 ).

This was confirmed by the traditional leaders. KI_G2 also described the health of the Barotse floodplain community during floods as very poor: 
Perceived prevalence of waterborne diseases in the Barotse floodplain was rated as very high $(77.1 \%)$ (Figure 3; Table 4) during the flood season. There is no difference between perceptions of men and women respondents regarding prevalence of water borne disease or types of diseases (Table 4). However, diarrhoea (33.3\%) was identified as second to malaria (58.6\%) when respondents were asked to identify the main diseases of concern (Table 4). Malaria was most frequently identified as the cause of poor health for all groups (family: 79.8\% respondents; children: $71.7 \%$ respondents; women: $56.6 \%$ respondents; men: $49.5 \%$ respondents). Diarrhea was cited as the second most frequent cause of poor health across all categories, again highest for families (60.6\%), children (51.5\%), women (44.4\%) and men (32.3\%). Ringworm was third frequent from children (17.1\%) and family $(15.5 \%)$ health, while no health issues was third frequent for women (14.1\%) and men (13.1\%). Cough and fever $(10.1 \%$ respondents each) were ranked fourth and fifth for children's health. Of note, foot wounds were identified for men (3.0\% respondents) due to the work that they do, and feminine hygiene was noted by two respondents for women's health. One village headman confirmed the common type of illnesses in the floodplain as follows:

"Malaria and diarrhoea are the most prevalent diseases during the floods in Barotse floodplain. This is because we drink contaminated water. Mosquitoes are also common during the floods in the floodplain, hence causing malaria" (KI_T3)

This was echoed by one of the survey respondents:

"The source has become bad to the extent that people get sick to drink water from the source especially those who go just to visit because they are not used." Survey respondent

KI_G2 noted that the common health problems prevalent in the Barotse floodplain during the flood include malaria, diarrhoea, and malnutrition. These were attributed to prevalence of malaria during the floods, water pollution caused by submerged pit latrines, and lack of food. Children were identified as the most affected followed by women. While policies are in place to reduce poverty and disease, KI_G2 indicated that health care provision in the floodplain focused mainly on under-five services, family planning, and general medical services.

Where provision of health services in the floodplain is concerned, the traditional leaders' assertion was that there are health providers in the Barotse floodplain who provide health services such as antenatal and under-five services to the women and children/babies. The health providers do not however provide medicines to treat most of the illnesses prevalent in the floodplain mostly because clinics do not have drugs so in most cases, patients are only given prescriptions.

Most survey respondents held similar views. $83.8 \%$ of respondents reported that the closest clinic was at least an hour away, with $18.1 \%$ indicating that it was four to six hours away. When asked about service provision, diagnoses (48.5\%), medications (44.4\%) and treatment (34.3\%) were most often identified. 
$11.1 \%$ of responses referred to the lack of medications at the clinic and $14.1 \%$ responses indicated that the clinics provided nothing. When asked what the government has done to improve health service provisioning, $64.6 \%$ of respondents indicated nothing, while $25.3 \%$ indicated that a new clinic had been built, $3.0 \%$ noted a mobile clinic, $1.0 \%$ noted additional staff, and $1.0 \%$ noted a community health committee. However, $6.0 \%$ responses referred to lack of medications and $3.0 \%$ to the clinics being too far away. Regarding health improvements, most respondents (42\%) suggested that the Government should provide the Barotse community with mosquito nets during floods. Others said that medications should be made available in the few clinics found in the Barotse floodplain. Other suggestions proposed by respondents included building of more clinics in the area (14\%) including mobile clinics (13\%).

\section{Discussion}

The aim of this study was to investigate the extent of impact of seasonal flooding on water supply, sanitation, and health of the rural community in the Barotse floodplain. The study further explored the rural community's adaptation to floods. The annual floods impact negatively on the Barotse floodplain community in several ways. Firstly, the water becomes contaminated due to unsanitary conditions on the plains as the pit latrines are submerged and local inhabitants practice open defecation. As flood waters are the only source of domestic water available to the community, respondents are exposed to waterborne pathogens. Secondly, likely related to source water contamination, the study showed that selfreported disease burden is high in Barotse community during the flood, especially for children under the age of five. This is in line with $[23,24,6,15]$ who noted an increase in the risk of spreading of waterborne diseases during the flood in Barotse floodplain. The study findings also agree with $[25,26$, 27] who suggested that climate change may alter the incidence of waterborne diseases. The rural population as noted by [28] has limited access to basic services including schools, health centres, safe water supply and sanitation. Access to safe water and sanitation in the rural areas is estimated at $37 \%$ and $13 \%$, respectively [28]. There is also a relatively high incidence of water and sanitation related diseases as noted by [28], particularly diarrhoea, which results in high health costs to individuals and communities. This was agreeing with [29] who noted recently that diarrhoeal diseases are associated with poor water and sanitation.

With respect to adaptation measures in the study area, the survey showed that most respondents do nothing to protect water sources. This has contributed to a high rate of waterborne diseases in the area as only a few are able to disinfect their water with chlorine and/or boil floodwater before use. These practices, albeit at very low rates, are consistent with those reported by [9] who observed similar practices. In addition, owing to the impact of flooding on sanitation facilities observed in the study area, the Barotse community have changed their normal defecation practices of using the toilets to open water defecation. However, these strategies remain harmful to those who practice them. As such, they should be considered coping mechanisms and immediate, short-term responses to an adverse event - rather than sustainable adaptation strategies as observed by [30]. The study further showed that malaria is the main health 
problem prevalent in the area followed by diarrhoea. The prevalence of malaria in the study area according to the findings could be attributed to lack of provision of insecticide mosquito nets and preventive drugs by the government in the study area.

Information from policy documents examined in the study which included the National Water supply and Sanitation policy, National Climate Change Response Strategy as well as Rural Water and Sanitation Framework clearly indicates public responsibilities for establishing and provision of water supply and sanitation services in the country, and provision of technical and financial management of the mentioned utilities. The policy documents do not however, offer specific insights into the provision of water supply and sanitation in flood prone areas like the Barotse floodplain. There is no provision for the design, construction, operation and maintenance of water supply and sanitation facilities in the study area.

\section{Conclusion}

The study has demonstrated that flooding is a common feature in the Barose floodplain and affects the local people in the area in many ways. It reveals that floodwaters submerge drinking water wells and pit latrines. As a result, people are forced to contaminate the water bodies that they depend on for drinking water through open defecation practices. The study therefore has shown that the main impact of flood to water supply in the Barotse floodplain is water pollution. Further, sanitation facilities are adversely affected by the flood in the study area, and this has worsened the health of the Barotse floodplain community compared to the dry season. Because of this, most respondents in Barotse floodplain suffer from self-reported ill health and waterborne diseases. The study has also shown that the local community adopt temporary short-term measures to cope with flood impacts on water supply, sanitation, and ill health, but they have little capacity to adopt long-term measures that would protect their health. Therefore, collaboration between all relevant institutions, such as government departments and nongovernmental organisations, is required to support sustainable adaptation measures regarding water supply, sanitation, and health to cope with annual flooding in the Barotse floodplain.

These findings suggest that there is an urgent need for government and non-government organisations in Zambia engage in targeted programmes that aim at improving water and sanitation services, and health in the Barotse floodplain. This could be achieved through action such as:

a. Locating bore holes and water pumps on raised ground within the floodplain to provide safe clean water for domestic use and reduce waterborne diseases;

b. Providing water treatment (e.g., chlorine tablets) to all households during floods;

c. Constructing raised latrines on higher ground to prevent inundation that contaminates floodwaters and renders current latrines useless;

d. Ensuring an adequate supply of mosquito nets during the flood season;

e. Providing better access to health facilities in the Barotse floodplain, including through regular and frequent mobile clinics; 
f. Providing boats or on call water ambulances for improved emergency access to existing clinics, especially for maternal health purposes

g. Ensuring constant supply of sufficient medicines in the clinics serving floodplain communities

\section{Declarations}

\section{Ethics approval and consent to participate}

This research was approved by the Ethical committee from the University of Waterloo (ethical clearance number 43389) and the University of Zambia (ethical clearance number HSSREC 2021- May- 007).

All the methods were carried out in accordance with relevant guidelines and regulations in the ethics approval statement.

Informed consent was obtained from all subjects and/or their legal guardian(s) in the ethics approval statement

\section{Availability of data and materials}

The datasets used and/or analysed during the current study is available from the corresponding author on reasonable request. This is because data belongs to the Barotse community and that requests for it can be made through me.

\section{Funding}

Inonge Milupi post-doctoral research was supported by the Queen Elizabeth Postdoctoral Fellowship and University of Waterloo in Canada.

\section{Authors' contributions}

Inonge Milupi conceived and conducted the study. Corinne Schuster Wallace supervised data cleaning, analysis and writing. Craig Janes supervised the original study, and assisted with conceiving the original study, the original analysis, and writing. The authors read and approved the final manuscript.

\section{Acknowledgements}

We would like to thank all the government officials from the various ministries that were available during the interview in Mongu district of Zambia. We also thank all our respondents in the Barotse floodplain for the time they gave to this study. Finally, we thank the University of Waterloo in Canada and Queen 
Elizabeth Scholarship (QES) for funding the research. The authors are solely responsible for the content expressed in this manuscript.

\section{Authors' information}

Authors include a postdoctoral scholar in environment and professors in public health from public universities in Canada

\section{Author's informationh}

1 The University of Zambia, School of Education, Department of Language and Social Sciences Education. P.O BOX 32379, Lusaka, Zambia and 3. University of Waterloo, School of Public Health and Health Systems, LHN 2717,200 University Avenue West, Waterloo, Canada, 2. University of Saskatchewan, Department of Geography and Planning/Centre for Hydrology, Canada and 3.University of Waterloo, School of Public Health and Health Systems, LHN 2717,200 University Avenue West, Waterloo, Canada

\section{Consent for publication}

Not applicable.

\section{Competing interests}

The authors declare that they have no competing interests.

\section{References}

1. Alhassan, S., and Hadwen, W. L. (2017); Challenges and opportunities for mainstreaming climate change adaptation into WaSH development planning in Ghana. International journal of environmental research and public health, 14(7), 749.

2. Namafe, C. M. (2004); Flooding in the Context of the Barotse People of the Upper Zambezi Wetlands, Southern African Journal of Environmental Education, Vol. 21, 2004

3. Wanda, E. M., Manda, M., Kamlomo, D., Kushe, J., Mphande, C., Kaunda, J., and Msiska, O. (2017); Governing WASH for disaster risk reduction in Karonga Town, Malawi. International journal of disaster risk reduction, 26, 69-77.

4. Kohlitz, J. P., Chong, J., and Willetts, J. (2017); Climate change vulnerability and resilience of water, sanitation, and hygiene services: a theoretical perspective. Journal of Water, Sanitation and Hygiene for Development, 7(2), 181-195. 
5. Levy, K., Woster, A. P., Goldstein, R. S., and Carlton, E. J. (2016); Untangling the impacts of climate change on waterborne diseases: a systematic review of relationships between diarrheal diseases and temperature, rainfall, flooding, and drought. Environmental science \& technology, 50(10), 4905-4922.

6. Gaillard, J.-C., Pangilinan, R.M.M., Cadag, R.J. and Le Virginie, M. (2008); “Living with increasing floods: insight from a rural Philippine community", Disaster Prevention and Management, Vol. 17 No. 3, pp. 383 - 95.

7. Kreibich, H., Di Baldassarre, G., Vorogushyn, S., Aerts, J. C. J. H., Apel, H., Aronica, G. T., ArnbjergNielsen, K., Bouwer, L. M., Bubeck, P., Caloiero, T., Chinh, D. T., Cortès, M., Gain, A. K., Giampá, V., Kuhlicke, C., Kundzewicz, Z. W., Llasat, M. C., Mård, J., Matczak, P., ... Merz, B. (2017); Adaptation to flood risk: Results of international paired flood event studies. Earth's Future, 5(10), 953965. https://doi.org/10.1002/2017EF000606

8. Bello, N. N, Durosinmi, W. A. and Abdulkarim, R. I. (2017); Assessment of Adaptation Strategies to Flooding Impacts in Nigeria-A Review, Ctis, Volume 1, 2017, DOI: 10.31058/j.ud.2017.11001

9. Shimi, A. C., Parvin, G. A., Biswas, C., and Shaw, R. (2014); Impact and adaptation to flood: A focus on water supply, sanitation and health problems of rural community in Bangladesh, Disaster Prevention and Management Vol. 19 No. 3, pp. $298-313$

10. Dewan T. H (2015); Societal impacts and vulnerability to floods in Bangladesh and Nepal, Weather and Climate Extremes 7: 36-42

11. GRZ (2014); Environmental and social impact assessment for the improved use of priority traditional canals in the Barotse sub-basin of the Zambezi. BRM and NIRAS, V3, Final Report

12. Cai X, Haile A, Magidi J, Mapedza E, Nhamo L. (2017); Living with floods-household perception and satellite observations in the Barotse floodplain, Zambia Physics and Chemistry of the Earth 100: 27886.

13. Kampata, J.M, Parida, B.P, and Moalafhi, D.B. (2008); Trend analysis of rainfall in the headstreams of the Zambezi River Basin in Zambia. Physics and Chemistry of the Earth, Parts A/B/C 2008; 33(8): 621-5.

14. Siyupwa, K. E. (2018); Opportimising Use of The Barotse Flood Plain for Socio - Economic Development of Western Province, Zambia, The International Journal of Multi-Disciplinary Research, Paper-ID: CFP/703/ ISBN: 978-9982-70-318-5 www.ijmdr.net

15. Mahmood, A. (2004); "Flood impacts on rural water supply and sanitation and mitigation options", Proceedings of the National Workshop on Options for Flood Risk and Damage Reduction in Bangladesh, 7-9 September, Dhaka.

16. Inonge Milupi. D, Njungu, M, Moonga, S. M., Namafe, C. M, Monde, P. N, and Simooya, S. M (2019); "Climate Change Impacts, Vulnerability, and Adaptation Options among the Lozi Speaking People in the Barotse floodplain of Zambia". International Journal of Humanities Social Sciences and Education (IJHSSE), vol.6, no.9, pp. 149-157. doi: http://dx. doi.org/10.20431/ 23490381.0609017. 
17. Madzudzo, E., Mulanda, A., Nagoli, J., Lunda, J. and Ratner, B.D. (2013); A Governance Analysis of the Barotse Floodplain System, Zambia: Identifying Obstacles and Opportunities. CGIAR Research Program on Aquatic Agricultural Systems. Penang, Malaysia. Project Report: AAS-2013-26.

18. Inonge Milupi, D., Mirriam Sampa Moonga and Bernard Chileshe (2020); Transmission mechanisms of Traditional Ecological Knowledge and sustainable management of natural resources among the Lozi-speaking people in Barotse floodplain of Zambia Multidisciplinary Journal of Language and Social Sciences Education | Volume 3, Issue 2. pp 24 - 42

19. Mirrian Sampa Moonga and Inonge Milupi (2015); Transmission mechanisms of Local Ecological Knowledge in Zambia: The case of the Lozi-speaking people of Western Province, Research paper presented at the 5th African RCE Conference, Kampala, Uganda

20. GRZ (Government of the Republic of Zambia) (2020); National Water supply and sanitation, Ministry of Water Development, Sanitation and Environmental Protection

21. GRZ (Government of the Republic of Zambia) (2010): National Climate Change Response Strategy (NCCRS) Zambia, Ministry of Tourism, Environment and Natural Resources, Final Draft

22. NWASCO (National Water Supply and Sanitation Company) (2018); Rural Water Supply and Sanitation Framework for Provision and Regulation in Zambia

23. Kateule E, Mzyece H, Kalubula P, Mwangala S, Inambao B, Mukanwa N, Sinyange N, Kapina M, Mukonka V.M. (2020); An Outbreak of Diarrhoeal Disease Attributed to Contaminated Drinking Water, Nalolo District, Zambia - 2019. Health Press Zambia Bull 04 (2); pp 11-15.

24. Thiam, S., Diène, A. N., Sy, I., Winkler, M. S., Schindler, C., Ndione, J. A., Faye. O., Vounatsou, P, Jürg U and Cissé, G. (2017); Association between childhood diarrhoeal incidence and climatic factors in urban and rural settings in the health district of Mbour, Senegal. International journal of environmental research and public health, 14(9), 1049.

25. Levy, K., Smith, S. M., and Carlton, E. J. (2018); Climate change impacts on waterborne diseases: moving toward designing interventions. Current environmental health reports, 5(2), 272-282.

26. Davies, G. I., Mclver, L., Kim, Y., Hashizume, M., Iddings, S., and Chan, V. (2015); Water-borne diseases and extreme weather events in Cambodia: Review of impacts and implications of climate change. International journal of environmental research and public health, 12(1), 191-213.

27. Levy, K., Woster, A. P., Goldstein, R. S., \& Carlton, E. J. (2016); Untangling the impacts of climate change on waterborne diseases: a systematic review of relationships between diarrheal diseases and temperature, rainfall, flooding, and drought. Environmental science \& technology, 50(10), 4905-4922.

28. Horn, L. M., Hajat, A., Sheppard, L., Quinn, C., Colborn, J., Zermoglio, M. F., and Ebi, K. L. (2018); Association between precipitation and diarrheal disease in Mozambique. International journal of environmental research and public health, 15(4), 709.

29. NFNCZ (National Food and Nutrition Commission of Zambia) (2020); Policy Brief, Improving water supply, Sanitation and Hygiene: A prerequisite to Improving child nutrition.

30. Parvin G. and Shaw R (2010); Impact and adaptation to flood: A focus on water supply, sanitation, and health problems of rural community in Bangladesh, Article in Disaster Prevention and 
Figures

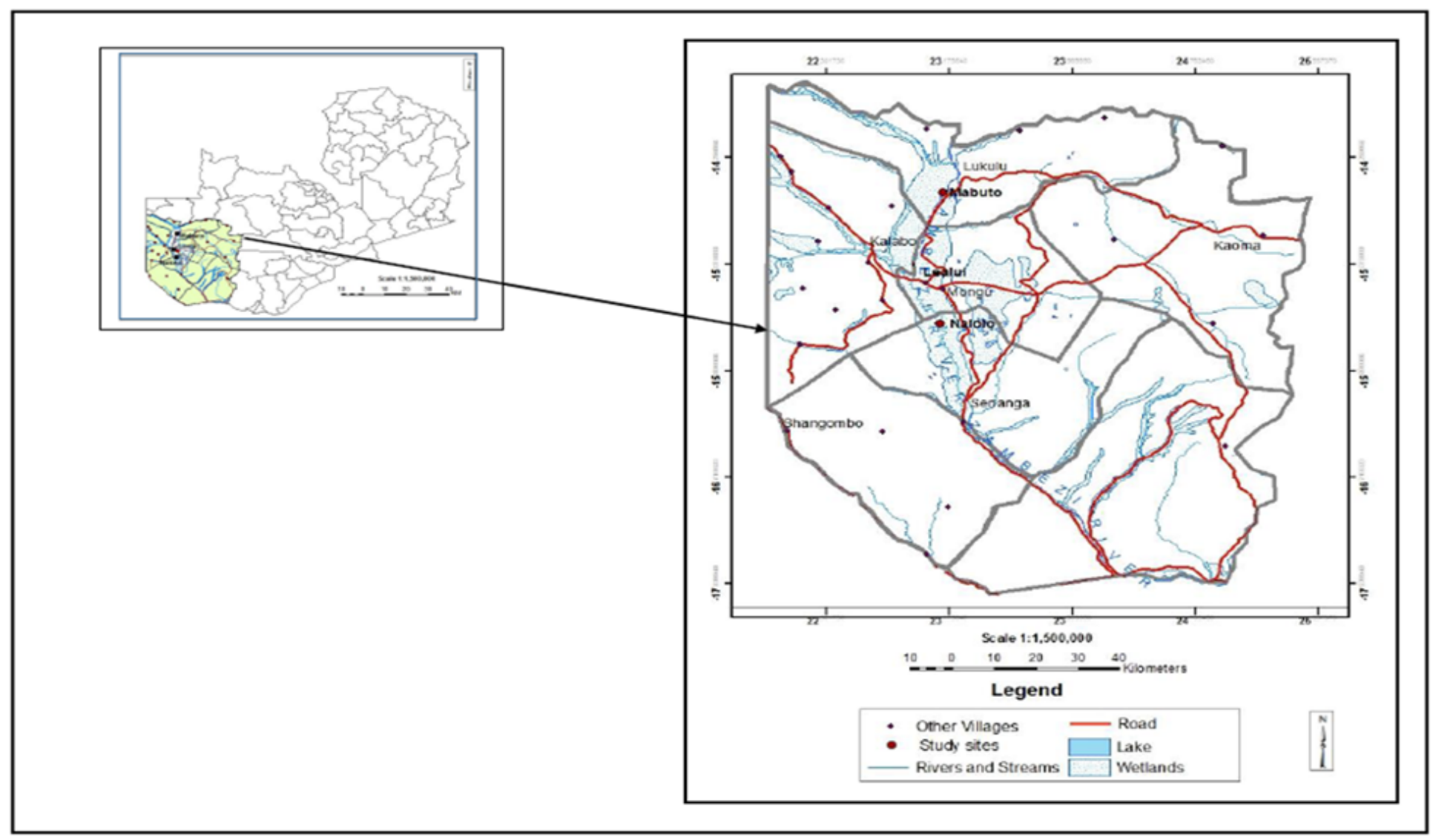

Figure 1

Map of Zambia showing the location of the Barotse floodplain 
- Poor Quality - Dirty - Contaminated - Degraded - Nolmpact - Did not answer

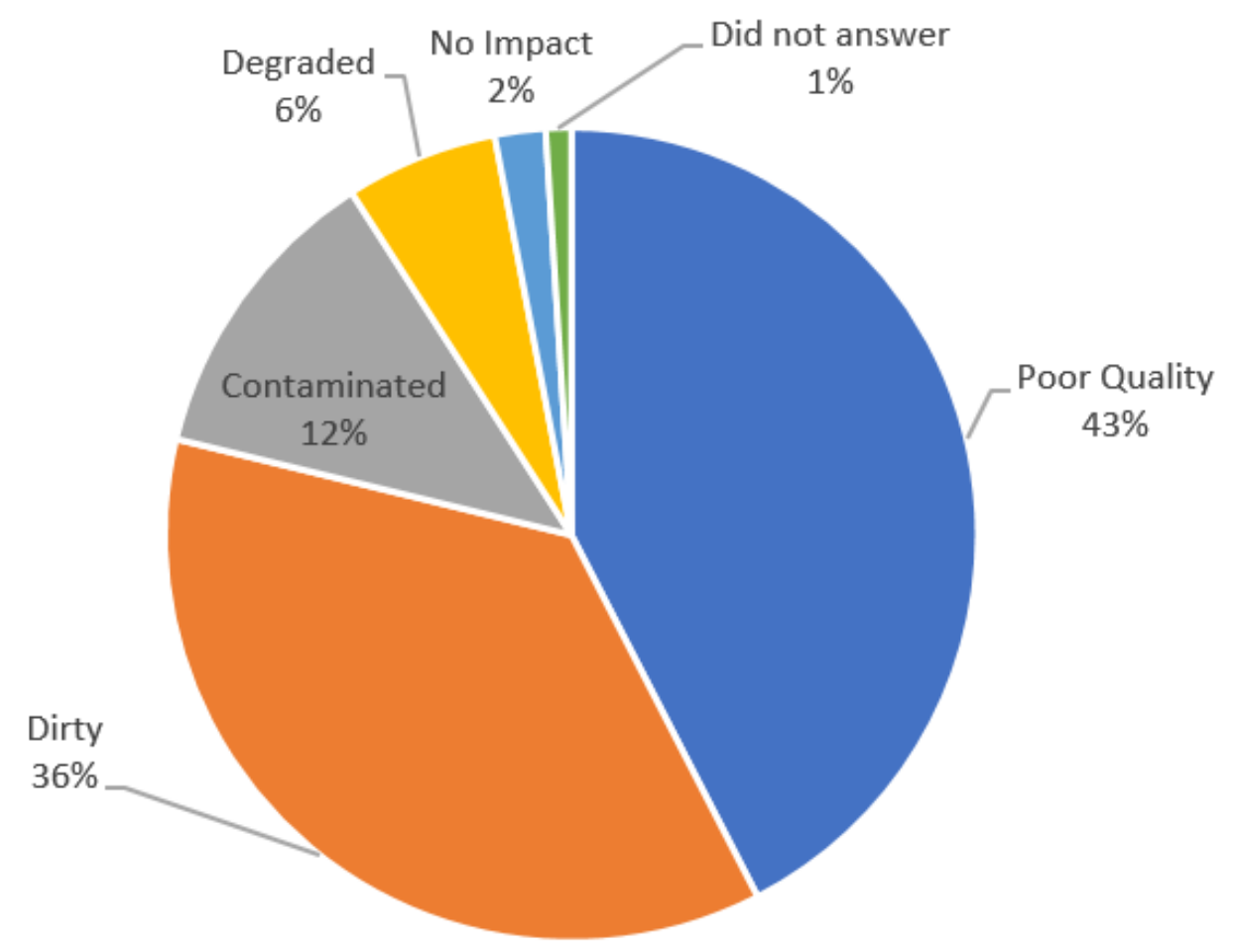

Figure 2: Showing responses on the impact of flood on water quality in Barotse flood plains.

Figure 2

Please See image above for figure legend. 


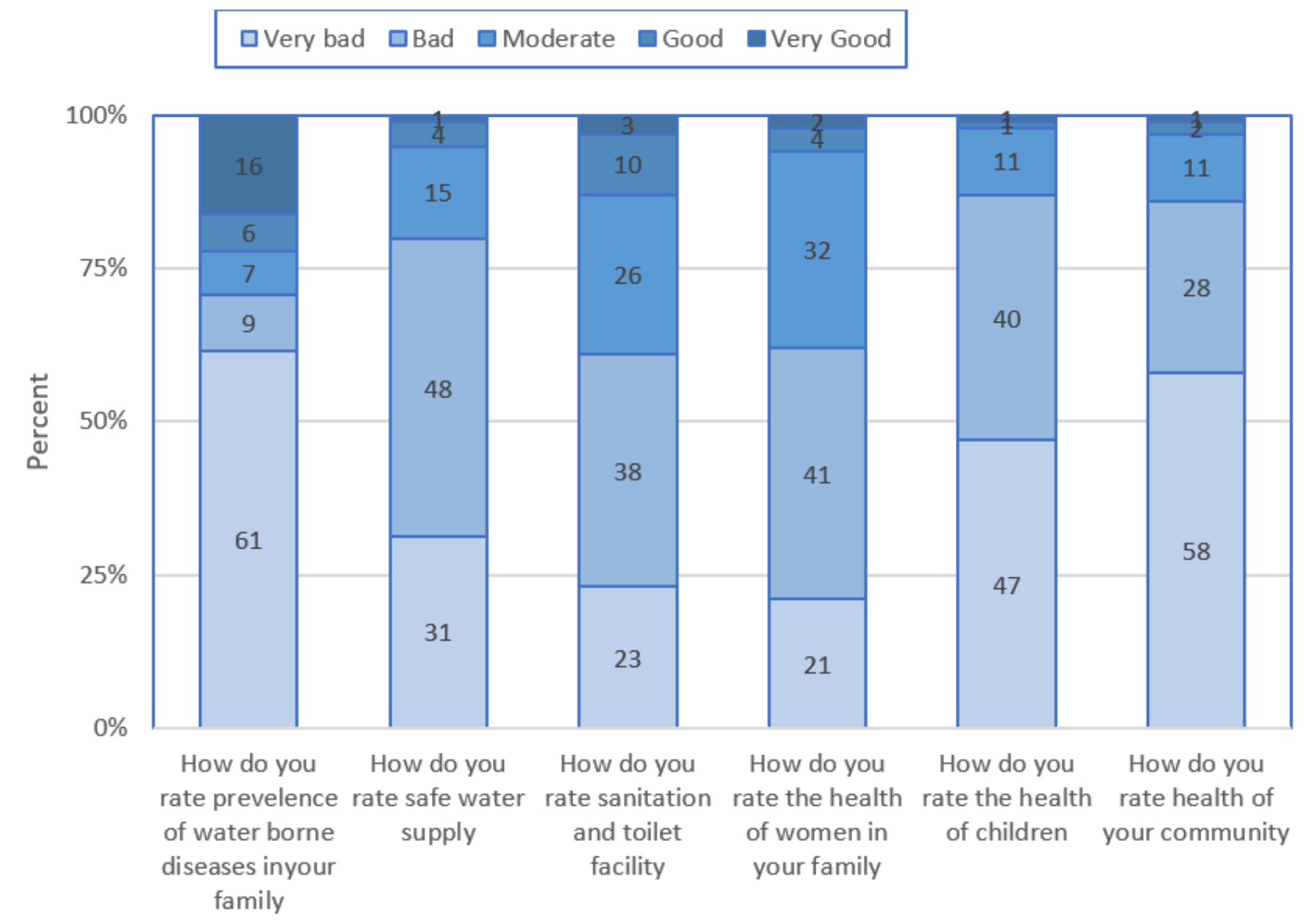

Figure 3

Respondents ratings of health of their family and community 